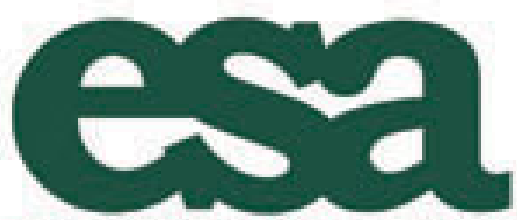

Promoting the Science of Ecology

\title{
Behavioral Interactions Among Four Species of the Salamander Genus Desmognathus
}

Author(s): Mark T. Southerland

Source: Ecology, Vol. 67, No. 1 (Feb., 1986), pp. 175-181

Published by: Ecological Society of America

Stable URL: http://www.jstor.org/stable/1938516

Accessed: 17/02/2009 09:38

Your use of the JSTOR archive indicates your acceptance of JSTOR's Terms and Conditions of Use, available at http://www.jstor.org/page/info/about/policies/terms.jsp. JSTOR's Terms and Conditions of Use provides, in part, that unless you have obtained prior permission, you may not download an entire issue of a journal or multiple copies of articles, and you may use content in the JSTOR archive only for your personal, non-commercial use.

Please contact the publisher regarding any further use of this work. Publisher contact information may be obtained at http://www.jstor.org/action/showPublisher?publisherCode=esa.

Each copy of any part of a JSTOR transmission must contain the same copyright notice that appears on the screen or printed page of such transmission.

JSTOR is a not-for-profit organization founded in 1995 to build trusted digital archives for scholarship. We work with the scholarly community to preserve their work and the materials they rely upon, and to build a common research platform that promotes the discovery and use of these resources. For more information about JSTOR, please contact support@ jstor.org. 


\title{
BEHAVIORAL INTERACTIONS AMONG FOUR SPECIES OF THE SALAMANDER GENUS DESMOGNATHUS ${ }^{1}$
}

\author{
MARK T. SOUTHERLAND ${ }^{2}$ \\ Department of Biology, University of North Carolina at Chapel Hill, \\ Chapel Hill, North Carolina 27514 USA
}

\begin{abstract}
Four sympatric species: Desmognathus quadramaculatus, D. monticola, D. fuscus, and D. ochrophaeus, showed different substrate preferences in experimental trials. In addition, the choices of substrates and of cover objects were influenced by the presence of other salamanders. Significant differences in substrate choice were found for each pair of species. The ratio of rocky to woody substrate chosen was lower for the more terrestrial species. The ecologically intermediate species, $D$. monticola, exhibited the broadest choice of substrate and shifted its choice when confined with congeners. Adults of $D$. monticola became more active and avoided the preferred substrate of $D$. quadramaculatus when confined with that species. Juveniles of $D$. monticola became less active but also avoided preferred substrates of the larger D. quadramaculatus. In $1-\mathrm{m}^{2}$ arenas with four cover objects, small individuals of the three more terrestrial species avoided cover occupied by large individuals of these species. No aggressive behavior patterns were observed in 100 encounters of different individuals. These results suggest that this assemblage of salamanders is structured by species-specific microenvironmental preferences that are affected by interspecific interactions. Avoidance of other salamanders is the common response that segregates individuals and species. This avoidance is likely an adaptation to the severe risk of predation faced by small salamanders.
\end{abstract}

Key words: behavior; community; Desmognathus spp.; habitat selection; interference; predation; refuge sharing; salamander; southern Appalachians; substrate choice.

\section{INTRODUCTION}

Currently 11 species are recognized in the salamander genus Desmognathus. Commonly three, and up to six, congeneric species may be sympatric. Several studies (Hairston 1949, Organ 1961, Krzysik 1979) have compared different species assemblages and concluded that interspecific interactions are important in determining their structure. Early interpretations inferred the effects of interspecific competition from the consistent differences in spatial pattern and body size among the species. Krzysik (1979) maintained this view based on his observations of low overlap between species in microhabitat preferences correlated with body size. Other investigators (Tilley 1968, Huheey and Brandon 1973, Hairston 1980) have reported that predation by congeners might be a factor in determining the distribution and abundance of these species. Hairston (1980) has advanced the view that competition alone is not sufficient to explain the structure of Desmognathus communities. This view is based on the fact that the relatively smaller size of those species found in more terrestrial habitats is inconsistent with the concept of competitive efficiency, as small size necessarily increases evaporative water loss.

The importance of interspecific interactions in structuring assemblages of similar species continues to be a central question in ecological research (Strong et al. 1984). The relative importance of competition and pre-

\footnotetext{
${ }^{1}$ Manuscript received 17 September 1984; revised 20 January 1985; accepted 28 January 1985.

${ }_{2}^{2}$ Present address: Smithsonian Environmental Research Center, P.O. Box 28, Edgewater, Maryland 21037 USA.
}

dation in producing this structure is also of great interest (Hairston et al. 1960, Connell 1975, Menge and Sutherland 1976). The determination of whether one or both of these factors are producing the structure seen in the genus Desmognathus has broad implications for community ecology.

One way to test for the presence of competitionbased and predation-based interactions among these species is to perform behavioral trials. The existence of aggression and predation can be directly observed, and avoidance can be revealed through the effects of congeners on habitat selection. Behavioral interactions of this type can have profound consequences on community structure (Morse 1980). Because Desmognathus species form a series of increasingly terrestrial habit (Hairston 1949), and show different, but overlapping, habitat preferences, artificial habitat enclosures in the field can be used to study their habitat selection. In this way, it is possible to discover both species-specific habit preferences and shifts in habitat choice in the presence of congeners (Keen 1982).

Observations of individual salamanders in laboratory containers have yielded many examples of aggression and related behavioral responses (for Plethodon cinereus, Jaeger 1981, 1984; for $P$. jordani and $P$. glutinosus, Nishikawa 1985; and for Desmognathus monticola, Nelson 1979, Keen and Sharp 1984). In laboratory experiments, certain Desmognathus species demonstrate fidelity to substrate type. In trials with large boards as cover objects, preferences for the underlying substrate have been shown to be influenced by $\mathrm{pH}$ (Mushinsky and Brodie 1975), particle size (Krzysik and Miller 1979, Keen 1982), and moisture 
(Keen 1982). Although other organisms, e.g., Anolis lizards (Jenssen 1973) and desert rodents (Price 1978), have exhibited shifts in structural habitat in the presence of presumed competitors, Keen (1982) did not find significant shifts in substrate choice when either D. monticola or D. fuscus was confined with the other. In Keen's laboratory studies each species maintained its original preferences for substrate texture and moisture. No studies have attempted to document habitat shifts due to predation pressure on salamanders, as has been done for crayfish (Stein and Magnuson 1976) and minnows (Fraser and Cerri 1982) in the presence of predatory fish.

Four sympatric species of Desmognathus: D. quadramaculatus, D. monticola, D. fuscus, and D. ochrophaeus, occur in the southern Appalachians. These species possess distinctly different maximum body sizes $(100,75,65$, and $50 \mathrm{~mm}$ snout-to-vent length, respectively) and habitat preferences (stream, coarse-grained streambank, fine-grained streambank, and forest floor, respectively). This assemblage offers an ideal opportunity for the investigation of interspecific interactions in this genus.

\section{Methods}

I chose a site at $995 \mathrm{~m}$ elevation in Boone, North Carolina, where all four species are abundant. The site borders a second-order tributary of the South Fork of the New River. I then developed two contrasting experimental designs to determine substrate choices, both of individuals alone and in the presence of other individuals, and to observe behavioral interactions between individuals.

\section{Substrate choice}

For the substrate experiments I chose three coarse substrates into which salamanders could burrow: large $\left(\approx 50 \mathrm{~cm}^{2}\right.$ top surface area) and small $\left(10 \mathrm{~cm}^{2}\right)$ rocks collected from the streambed and small $\left(10 \mathrm{~cm}^{2}\right)$ pieces of woody debris collected from the forest floor. I placed a $5-\mathrm{cm}$ layer of the substrates on the plastic bottom of $0.5 \mathrm{~m}$ diameter arenas with $0.3 \mathrm{~m}$ high sheet-metal sides. The substrates were arranged by type into three pie-shaped sectors, with each arena possessing a unique arrangement of substrates relative to compass direction. Stream water was added to keep the substrates wet and fine-mesh hardware-cloth lids were placed over each arena to prevent the escape of the salamanders. I placed 12 of these arenas in a homogeneous area of forest floor $\approx 10 \mathrm{~m}$ from the stream.

Two records of location were made for each individual salamander placed in an arena. After $30 \mathrm{~h}$ the first observation was made between dusk and 2300; a second observation was made in the afternoon of the following day. Each salamander used was collected from the nearby streamside area; no salamander was used for more than one trial. For each record, the instantaneous location of the individual was identified by substrate type (SUBSTRATE), by whether the salamander was on top of or beneath the substrate (LEVEL), and by whether the salamander was prone, raised on forelimbs, or climbing the arena wall (ACTIVITY). I also kept records of daily rainfall and of the air temperature at the time of the observation.

In the first experiment, I tested 144 salamanders in individual trials. Twelve individuals, one from each combination of the four species (SPECIES) and the three sex/age classes (SEX) (adult male, adult female, and juvenile) were tested simultaneously in the 12 arenas, one salamander in each arena. Twelve replicate trials for each of these salamander categories were run consecutively, one trial in each of the 12 different arenas. These sequential trials were allocated to arenas so that no salamander type followed another particular type in any arena more than once.

In the second experiment, I placed individual $D$. monticola in arenas with a second salamander. I designed six treatments involving conspecific or congeneric pairs: (1) two adult $D$. monticola (mean snoutto-vent length [SVL] $=53 \mathrm{~mm}$ ) of the same sex, (2) two juvenile $D$. monticola (mean SVL $=32 \mathrm{~mm}$ ), (3) an adult $D$. monticola and an adult $D$. quadramaculatus of the same sex and size (mean SVL $=55 \mathrm{~mm}$ ), (4) a juvenile $D$. monticola and an adult male or female D. ochrophaeus of equal size (mean $\mathrm{SVL}=38 \mathrm{~mm}$ ), (5) a $D$. monticola and a $D$. fuscus (either both adults or both juveniles) of equal size (mean SVL $=45 \mathrm{~mm}$ ), and (6) a juvenile $D$. monticola (mean SVL $=30 \mathrm{~mm}$ ) and an adult male or female $D$. quadramaculatus (mean SVL $=66 \mathrm{~mm}$ ) of twice or greater SVL. I also ran a seventh treatment, designed as a test for interactions outside the genus, in which I paired a juvenile $D$. monticola with a Eurycea bislineata of equal size (mean $\mathrm{SVL}=33 \mathrm{~mm}$ ). E. bislineata is a member of a different subfamily, the Hemidactyliinae, and is the most common non-desmognathine found near the stream. Twelve replicate trials for each treatment were run consecutively with unique individuals assigned to each of the 12 different arenas. I performed both these experiments between 25 June and 21 September 1982.

\section{Refuge sharing}

In this experiment, I constructed four $1-\mathrm{m}^{2}$ circular arenas by sinking sheet-metal strips into the soil of a wet streambank area. Waterproof tape was curled over the top of the arena wall to prevent the escape of the salamanders. To each arena I added four cover objects $\left(100-\mathrm{cm}^{2}\right.$ flat rocks). Four salamanders were placed in each arena for each set of observations. Specific combinations of different salamander types were used so that each pairwise combination occurred 40 times. Five types of semiterrestrial salamanders were used: adult D. monticola (mean SVL $=54 \mathrm{~mm}$ ), juvenile $D$. monticola (mean SVL $=32 \mathrm{~mm}$ ), adult $D$. fuscus (mean $\mathrm{SVL}=52 \mathrm{~mm}$ ), juvenile $D$. fuscus (mean $\mathrm{SVL}=33$ $\mathrm{mm}$ ), and adult $D$. ochrophaeus (mean SVL $=35 \mathrm{~mm}$ ). 
D. quadra-

maculatus

D. monticola

D. fuscus
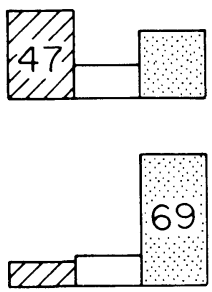

D. ochrophaeus

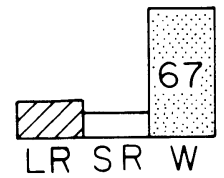

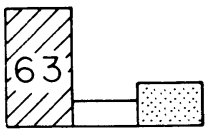
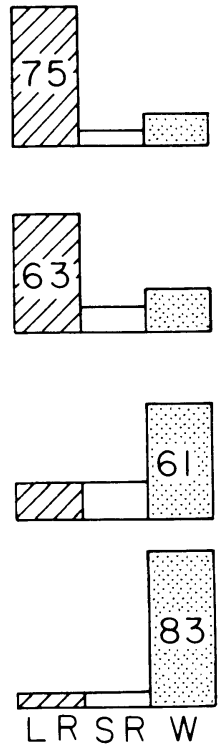

FIG. 1. Substrate choice patterns for lone individuals of each Desmognathus species (all sex/age classes combined) during night and day trials. Substrate types: $L R=$ large rocks; $\mathrm{SR}=$ small rocks; and $\mathrm{W}=$ wood. Column heights indicate the percentage of each substrate type chosen. For the preferred substrate, the percentage is shown numerically within the appropriate column. 


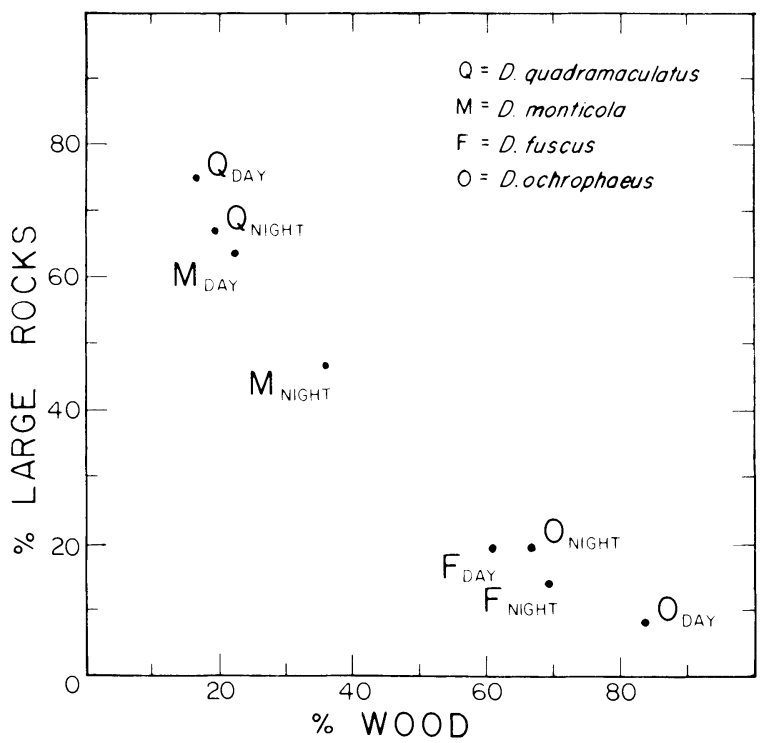

FIG. 2. Segregation and substrate choice by lone individuals of four species of Desmognathus along the axes of the two most preferred substrates. Night and day observations are considered separately.

frequently by all species, species' substrate preferences (both night and day) segregated principally with respect to the choice of large rocks vs. wood (Fig. 2). Of the species adjacent to each other in the aquatic-to-terres-

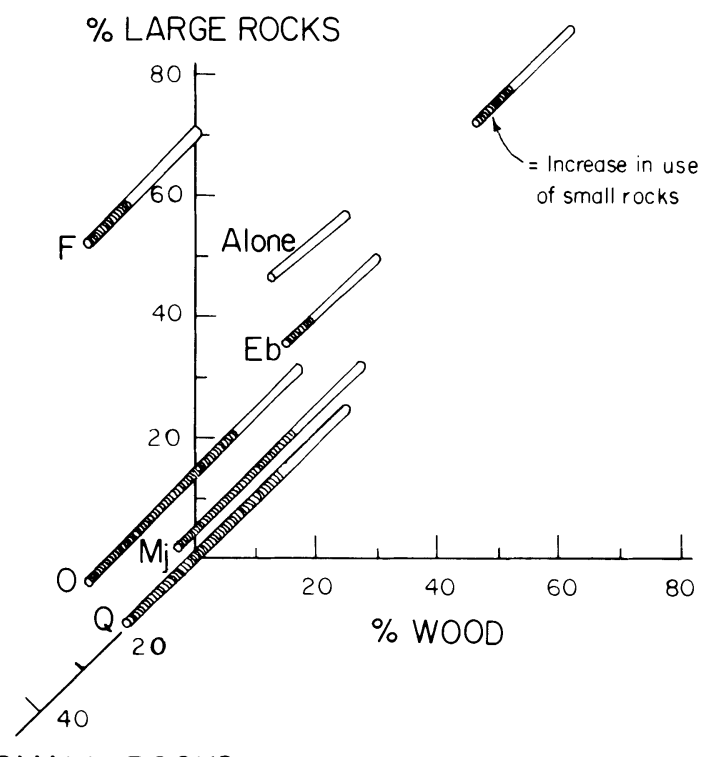

$\%$ SMALL ROCKS

FIG. 3. Diurnal substrate choice of juvenile Desmognathus monticola (shown in three-dimensional space with one axis for each substrate) in five trials. Cylinders indicate amount of small rocks chosen; shaded portions show increase in the presence of the second salamander. Alone $=$ substrate preference of solitary juvenile $D$. monticola; $\mathrm{Eb}=$ substrate choice when paired with Eurycea bislineata $; \mathrm{F}=$ choice when paired with D. fuscus; $\mathbf{M}_{\mathrm{j}}=$ choice when paired with a second juvenile $D$. monticola; $\mathrm{O}=$ choice when paired with $D$. ochrophaeus; $\mathrm{Q}=$ choice when paired with $D$. quadramaculatus.
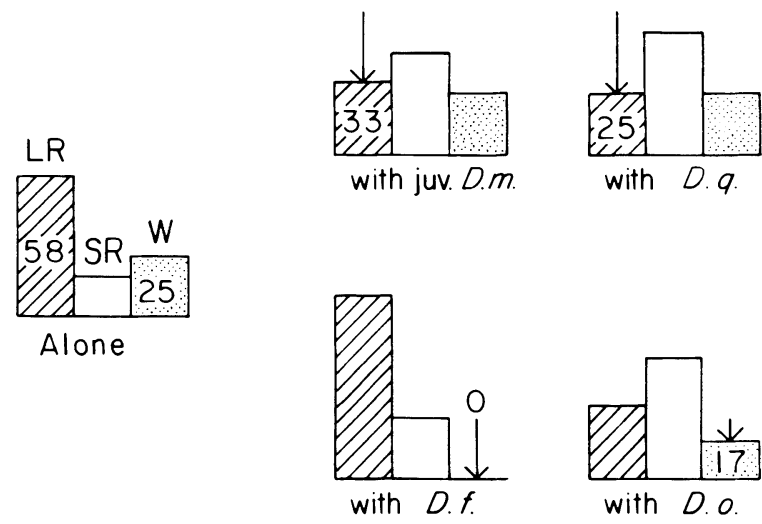

FIG. 4. Shifts in the diurnal substrate choice of juvenile Desmognathus monticola when paired with a second salamander. juv. $D . m .=$ juvenile $D$. monticola D. $f .=D$. fuscus and $D . o .=D$. ochrophaeus (salamanders of equal size); and D. $q .=$ D. quadramaculatus (salamanders of twice or greater snout-vent length). Percentages are shown numerically in the preferred substrate of the salamanders with which the juvenile D. monticola were paired. Length of arrow shaft indicates the magnitude of the decrease in use of this substrate by juvenile D. monticola. Other abbreviations are as in Fig. 1.

trial series, the $D$. fuscus $-D$. ochrophaeus pair in night observations and the D. quadramaculatus-D. monticola pair in day observations were the most similar.

In comparisons of the substrate choice frequencies of each pair of these species, significant differences $(G$ test with the Williams' correction; Sokal and Rohlf 1981) at the level of $P<.0083$ (adjusted for all possible comparisons: $\alpha=.05 / 6$ ) were found in four of the six night and five of the six day comparisons. The differences between either $D$. quadramaculatus or $D$. monticola and D. fuscus and D. ochrophaeus were highly significant $(P<.001)$. Diurnal substrate choice difference between $D$. fuscus and $D$. ochrophaeus was also significant $(P=.007)$. The differences in substrate preferences among sex/age classes (males, females, and juveniles) were much smaller, the major difference being that juveniles chose wood more often than adults did. This age class effect, however, was weaker than the species effect. For example, juvenile $D$. monticola (mean $\mathrm{SVL}=29 \mathrm{~mm}$ ) still preferred large rocks significantly more (night: $G_{\text {adj }}=6.31, P=.04$; day: $G_{\text {adj }}=15.5$, $P<.001$ ) than did adult $D$. fuscus (mean $\mathrm{SVL}=34$ $\mathrm{mm}$ ) and adult $D$. ochrophaeus (mean SVL $=32 \mathrm{~mm}$ ).

In the paired-salamander experiment, the substrate preferences identified in the first experiment were compared with substrate choices of salamanders confined with a second salamander. Because D. monticola, especially juveniles, exhibited intermediate substrate preferences (Fig. 2) when compared with the other species, the paired-salamander trials were designed to detect interactions between salamanders by revealing shifts in the substrate choice of $D$. monticola. Secondarily, the substrate choices of the other salamanders were compared with the preferences indicated for their 


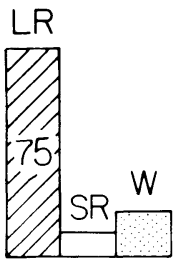

Alone

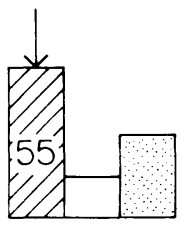

with adult $D . m$.

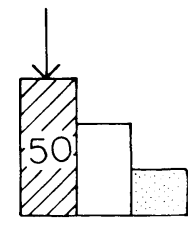

with D.q.
FIG. 5. Shifts in the diurnal substrate choice of adult Desmognathus monticola when paired with a second salamander. $D . m$. $=$ adult $D$. monticola and $D . q .=D$. quadramaculatus (salamanders of equal size). Arrows and other abbreviations are as in Fig. 4.

species in the first experiment. In this way, avoidance between salamanders can be inferred from changes in substrate choice.

Both adult and juvenile $D$. monticola significantly shifted their diurnal substrate choice pattern in the presence of $D$. quadramaculatus (adult: $G_{\text {adj }}=6.38$, $P=.04$; juvenile: $G_{\text {adj }}=7.67, P=.02$ ). Juvenile $D$. monticola also significantly shifted their substrate choice pattern when paired with a second juvenile $D$. monticola (day: $G_{\text {adj }}=8.88, P=.01$ ). Shifts by juvenile $D$. monticola in the presence of $D$. fuscus (day: $G_{\text {adj }}=$ $6.59, P=.04$ ) and $D$. ochrophaeus (day: $G_{\text {adj }}=6.72$, $P=.04$ ) were nonsignificant when the level of significance was adjusted for multiple comparisons with the same control $(\alpha=.05 / 3=.02)$. Juvenile $D$. monticola did not shift their substrate choice when paired with equal-sized individuals of the hemidactyline salamander Eurycea bislineata (day: $G_{\text {adj }}=2.82, P=.25$ ).

When these substrate choice shifts of juvenile $D$. monticola are plotted in three-dimensional space (Fig. 3 ), two major responses can be seen: (1) an increase in the choice of the least preferred substrate (small rocks), and (2) a decrease in the choice of the preferred substrate of the second salamander (large rocks for $D$. quadramaculatus and D. monticola, and wood for $D$. fuscus and $D$. ochrophaeus). The length of the arrows in Figs. 4 and 5 indicates the degree to which D. monticola chose large rocks less often when paired with $D$. quadramaculatus and wood less often when paired with D. fuscus or D. ochrophaeus.

A less powerful method to determine if these salamanders were interacting is to compare records of individuals observed in the same sector, with the random expectation of $33 \%$ co-occurrence. Only the juvenile D. monticola-D. quadramaculatus (night and day: $G_{\text {adj }}=4.69, P=.03$ ) and the two juvenile $D$. monticola (night: $G_{\text {adj }}=26.3, P<.001$; day: $G_{\text {adj }}=11.8, P<$ $.001)$ trials showed significantly fewer instances of cooccurrence.

Of the other salamanders, only $D$. fuscus significantly changed its choice of substrate when paired with D. monticola (night: $G_{\text {adj }}=6.18, P=.04$; day: $G_{\text {adj }}=$ $6.42, P=.04)$. Its choices were spread more evenly among the different substrates when paired with ju-
TABLE 2. Observations of Desmognathus salamanders under cover objects within enclosures. Each individual was recorded as "alone" or as "paired" (under same cover object) for each individual with which it was confined.

\begin{tabular}{lc}
\hline \hline \multicolumn{1}{c}{ Salamander combination } & $\begin{array}{c}\text { Per- } \\
\text { centage } \\
\text { paired* }\end{array}$ \\
\hline Adult $D$. monticola-adult $D$. monticola & 21 \\
Adult $D$. monticola-adult D. fuscus & 29 \\
Adult $D$. fuscus-adult D. fuscus & 8 \\
Juvenile D. monticola-juvenile D. monticola & 8 \\
Juvenile D. monticola-juvenile D. fuscus & 19 \\
Juvenile D. monticola-adult D. ochrophaeus & 17 \\
Juvenile D. fuscus-juvenile D. fuscus & 13 \\
Juvenile D. fuscus-adult D. ochrophaeus & 20 \\
Adult D. ochrophaeus-adult D. ochrophaeus & 17 \\
Adult D. monticola-juvenile D. monticola & 6 \\
Adult D. monticola-juvenile D. fuscus & 11 \\
Adult $D$. monticola-adult $D$. ochrophaeus & 6 \\
Adult $D$. fuscus-juvenile D. monticola & 7 \\
Adult D. fuscus-juvenile D. fuscus & 15 \\
Adult D. fuscus-adult D. ochrophaeus & 18 \\
Total observations & 15 \\
\hline
\end{tabular}

* Records of paired observations are listed as percentages of all observations for each combination of salamander types. (Percentage expected under random assortment among cover objects $=35 \%$.)

venile D. monticola (Fig. 6) than when tested alone (Fig. 1). D. quadramaculatus showed no change in substrate choice pattern when paired with either adult or juvenile $D$. monticola, and $D$. ochrophaeus showed no change in substrate choice pattern when paired with juvenile $D$. monticola.

A comparison of level responses between substratepreference and paired-salamander trials revealed a surprising result in the $D$. monticola-D. quadramaculatus trials. Adult and juvenile $D$. monticola changed their nocturnal activity in opposite directions when confined with $D$. quadramaculatus. Adult $D$. monticola spent significantly more time above the substrate $\left(G_{\text {adj }}=8.51\right.$, $P=.004$ ), while juvenile $D$. monticola spent significantly more time below the substrate $\left(G_{\mathrm{adj}}=8.51, P=\right.$ $.004)$, when paired with $D$. quadramaculatus.

\section{Refuge sharing}

In the refuge-sharing experiment, I observed 100 instances where two salamanders, moving along the ground, came within $1 \mathrm{~cm}$ of each other. No actions

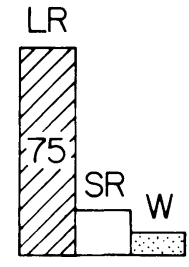

D. quadramaculatus

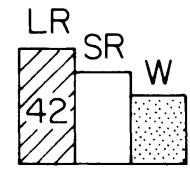

D. fuscus

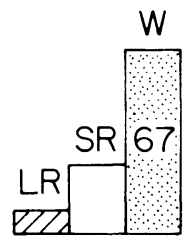

D. ochrophaeus
FIG. 6. Patterns of diurnal substrate choice in three species of Desmognathus salamanders when paired with $D$. monticola of equal size. Abbreviations are as in Fig. 1. 
that could be interpreted as aggression were seen, nor was predation observed. This contrasts with my own laboratory observations of intrageneric predation by all four species. However, on three occasions juvenile salamanders that had shared refuges with adult salamanders were discovered to have lost their tails.

In 600 records of refuge location, $15 \%$ found individuals sharing a refuge (Table 2 ). This is significantly lower than the expected $35 \%(G=130, P<.001)$. In trials of intraspecific pairs and of interspecific pairs, 11.7 and $16.1 \%$, respectively, were found sharing a refuge. These frequencies are not significantly different ( $G=2.38, P=.26$ ). In trials of pairs of equal-sized individuals, $19.0 \%$ shared refuges, but in trials of unequal-sized individuals only $9.7 \%$ shared refuges $(G=$ $10.8, P=.002)$. The most sharing of refuges was found between the equal-sized adult $D$. monticola and adult D. fuscus (29.4\%). The least sharing was found between the unequal-sized combinations of adult and juvenile D. monticola $(6.0 \%)$ and between adult $D$. monticola and adult $D$. ochrophaeus (6.0\%). The latter combinations are those where predation-based interactions are most likely to occur.

\section{Discussion}

The results of the substrate-choice and refuge-sharing experiments depict a community of salamanders with precise location-selection behaviors. In contrast to Keen's (1982) experiments, species-specific substrate preferences were affected by interspecific interactions. The magnitude of these interactions varied according to species and size class. Actual instances of aggressive or predatory encounters, however, were not observed. This contrasts with laboratory observations of aggression in D. monticola (Nelson 1979, Keen and Sharp 1984). I believe that a comparison of these disparate results must consider the effects of different experimental conditions.

\section{Substrate choice}

Previous studies on substrate choice in salamanders were all performed in the laboratory in constant darkness. I performed my study in enclosures in the field with a natural photoperiod. In addition, artificial cover objects were not added, as the substrate itself acted as cover, forming interstices in which the salamanders could take refuge. Also, unlike some studies, salamander substrate preferences can be ascribed to individual selection, as no encounters with other salamanders were involved. These preferences then can be contrasted with the choices in the paired-salamander trials where intraspecific and interspecific encounters might be important.

I suggest that the work of Krzysik and Miller (1979) and Keen (1982) did not show sharp habitat differences between species because they were manipulating moisture and substrate texture, rather than substrate type. While moisture is important in the habitat selection of desmognathine salamanders, the response of broader habitat choice with decreased desiccation stress is shown by all the species, with only small species differences. In contrast, differences in substrate texture may not reveal any differences in the responses of the species, because fine substrate-texture divisions, such as differences in particle diameter, are less likely to be perceived as different habitats than are different substrate types (e.g., rock vs. wood).

The design of two rocky substrates and one woody substrate was an attempt to mimic the aquatic-to-terrestrial habitat gradient found near mountain streams. The species did segregate by substrate choice patterns, as I expected (Fig. 2). These species differences are much greater than any sex or size differences. The variation in overlap between adjacent species-pairs suggests that $D$. quadramaculatus and $D$. monticola most completely share daytime refuges, while $D$. fuscus and $D$. ochrophaeus most completely share night or foraging habitat. Of the four species, D. monticola exhibited the broadest choice of substrate. In each trial, this intermediate species shifted away from the aquatic or terrestrial substrate when confined with a more aquatic or terrestrial congener, respectively. Only when confined with salamanders from a different subfamily, in this case $E$. bislineata, did D. monticola not shift away from a specific substrate. The adult $D$. monticola were more active in these paired trials, a possible response to some interference mechanism. The juvenile $D$. monticola, however, were less active and more often found under the substrate, a possible hiding mechanism when faced with predation pressure. The other intermediate species, D. fuscus, may also have been avoiding the second salamander, as they appeared to choose substrates more randomly (no preference among substrates) when confined with $D$. monticola. The largest species, D. quadramaculatus, did not appear to be influenced by the second salamander in their paired trials.

\section{Refuge sharing}

The observations of agonistic behavior in salamanders has been limited to laboratory trials, where containers with moist paper served as individual territories. Salamanders of the genus Plethodon may form territories around semipermanent burrows in the field. Desmognathus species, however, are more often found under objects near streams. These "cover objects" may be a limiting resource for protection against desiccation or as a base for foraging. However, when moisture conditions change significantly over short periods, desmognathine salamanders frequently shift refuges. Under these conditions, territorial defense may be rare.

In the $1-\mathrm{m}^{2}$ arenas, the four salamanders were limited to four refuges. Individuals sometimes remained under the same cover object for several days, but more often they shifted refuges after a night of surface activity. Although the salamanders always had a vacant refuge available to them, $15 \%$ of them were found sharing cover objects. However, this was much less refuge sharing than would be expected if the salamanders se- 
lected refuges randomly. Specifically, the smallest individuals, juvenile $D$. monticola, juvenile $D$. fuscus, and adult $D$. ochrophaeus, consistently avoided sharing refuges with large salamanders. I suggest that these salamanders were avoiding potential predatory encounters.

\section{CONCLUSION}

These four species of Desmognathus segregate by substrate choice according to their known habitat preferences. For the intermediate species, D. monticola, this selection of habitat location appears to be influenced by interactions with congeners. Juvenile $D$. monticola are most likely to shift their location as a result of their vulnerability to predation by large congeners. When seeking refuges, the other small species also exhibit avoidance of potential predatory congeners. Thesf results suggest that in natural environments, particularly along the stream-forest interface, desmognathines form an interactive community.

The presence of interactions, however, is dependent on the size, and consequently the species, of the sala. manders encountering each other. First of all, because encounters appear to be transitory, except possibly within refuges, I believe aggression is rare or absent during foraging. Also, I suggest that due to severe desiccation pressure, these salamanders must frequently seek new refuges, and do not often establish or defenc territories under cover objects. I conclude that the principal organizing factor in such communities is predation, especially on juveniles. Interference among larger salamanders may represent misguided attempts at predation, or may indicate true territorial defense of othe more valuable refuges (e.g., permanent burrows).

\section{ACKNOWLEDGMENTS}

I thank Nelson Hairston, Henry Wilbur, Haven Wiley, Seth Reice, George W. Cox, and two anonymous reviewers for their comments on this manuscript. I am also indebted to Dr. Hairston for his advice and support throughout my research. Wayne Van Devender directed me to the four-species site and first showed me its salamanders. Paul Townsend and Wink Winkleman kindly granted me access to their properties. Eliz. abeth and Cratis Williams and Agnes and Paul Townsend provided essential logistical support. Debra Southerland provided equally essential encouragement and support at home. This report was submitted as partial fulfillment of doctora' requirements at the University of North Carolina at Chapel Hill. The research was supported in part by a Joseph E. Pogue Research Fellowship and a Grant-in-Aid of Research from Sigma Xi, The Scientific Research Society.

\section{LiTERATURE Cited}

Connell, J. H. 1975. Some mechanisms producing structure in natural communities: a model and evidence from field experiments. Pages 460-490 in M. L. Cody and J. M. Diamond, editors. Ecology and evolution of communities. Harvard University Press, Cambridge, Massachusetts, USA.

Fraser, D. F., and R. D. Cerri. 1982. Experimental evaluation of predator-prey relationships in a patchy environment: consequences for habitat use patterns in minnows. Ecology 63:307-313.

$\rightarrow$ Hairston, N. G. 1949. The local distribution and ecology of the plethodontid salamanders of the southern Appalachians. Ecological Monographs 19:47-73.

- 1980. Species packing in the salamander genus Desmognathus: what are the interspecific interactions involved? American Naturalist 115:354-356.

Hairston, N. G., F. E. Smith, and L. B. Slobodkin. 1960. Community structure, population control, and competition. American Naturalist 94:421-425.

$\rightarrow$ Huheey, J. E., and R. A. Brandon. 1973. Rock-face populations of the mountain salamander, Desmognathus ochrophaeus, in North Carolina. Ecological Monographs 43: 59-77.

Jaeger, R. G. 1981. Dear enemy recognition and the costs of aggression between salamanders. American Naturalist 117:962-974.

1984. Agonistic behavior of the red-backed salamander. Copeia 1984:309-314.

Jenssen, T. A. 1973. Shift in the structural habitat of Anolis opalinus due to congeneric competition. Ecology 54:863869.

Keen, W. H. 1982. Habitat selection and interspecific competition in two species of plethodontid salamanders. Ecology 63:94-102.

Keen, W. H., and S. Sharp. 1984. Responses of a plethodontid salamander to conspecific and congeneric intruders. Animal Behaviour 32:58-65.

Krzysik, A. J. 1979. Resource allocation, coexistence, and the niche structure of a streambank salamander community. Ecological Monographs 49:173-194.

Krzysik, A. J., and E. B. Miller. 1979. Substrate selection by three species of desmognathine salamanders from southwestern Pennsylvania: an experimental approach. Annals of the Carnegie Museum 48:111-117.

Menge, B. A., and J. P. Sutherland. 1976. Species diversity gradients: synthesis of the roles of predation, competition, and temporal heterogeneity. American Naturalist 110:351369.

Morse, D. H. 1980. Behavioral mechanisms in ecology. Harvard University Press, Cambridge, Massachusetts, USA.

Mushinsky, H. R., and E. D. Brodie, Jr. 1975. Selection of substrate $\mathrm{pH}$ by salamanders. American Midland Naturalist 93:440-443.

Nelson, L. J. 1979. The aggressive behavior and chemical communication of the seal salamander, Desmognathus monticola. Thesis. Eastern Kentucky University, Richmond, Kentucky, USA.

Nishikawa, K. 1985. The ecology and evolution of aggressive behavior in two species of terrestrial salamanders. Dissertation. University of North Carolina at Chapel Hill, Chapel Hill, North Carolina, USA.

Organ, J. A. 1961. Studies of the local distribution, life history, and population dynamics of the salamander genus Desmognathus in Virginia. Ecological Monographs 31:189220.

Price, M. V. 1978. The role of microhabitat in structuring desert rodent communities. Ecology 59:910-921.

SAS Institute. 1982. SAS user's guide: statistics. 1982 edition. SAS Institute, Cary, North Carolina, USA

Sokal, R. R., and F. J. Rohlf. 1981. Biometry: the principles and practice of statistics in biological research. Second edition. W. H. Freeman, San Francisco, California, USA.

Stein, R. A., and J. J. Magnuson. 1976. Behavioral response of crayfish to a fish predator. Ecology 57:751-761.

Strong, D. R., Jr., D. Simberloff, L. G. Abele, and A. B. Thistle. 1984. Ecological communities: conceptual issues and the evidence. Princeton University Press, Princeton, New Jersey, USA.

Tilley, S. G. 1968. Size-fecundity relationships and their evolutionary implications in five desmognathine salamanders. Evolution 22:806-816. 